The implications of a feelings-based approach to fish welfare a reply to Arlinghaus et al

Huntingford, Felicity; Adams, Colin; Braithwaite, Victoria A.; Kadri, Sunil; Pottinger, Tom G.; Sandøe, Peter; Turnbull, James F.

Published in:

Fish and Fisheries

DOI:

doi:10.1111/j.1467-2679.2007.00254.x

Publication date:

2007

Document version

Publisher's PDF, also known as Version of record

Citation for published version (APA):

Huntingford, F., Adams, C., Braithwaite, V. A., Kadri, S., Pottinger, T. G., Sandøe, P., \& Turnbull, J. F. (2007).

The implications of a feelings-based approach to fish welfare: a reply to Arlinghaus et al. Fish and Fisheries, 8(3), 277-280. https://doi.org/doi:10.1111/j.1467-2679.2007.00254.x 


\title{
The implications of a feelings-based approach to fish welfare: A reply to Arlinghaus et al. ${ }^{1}$
}

\author{
F. Huntingford*, C. Adams*, V. A. Braithwaite+, S. Kadri*, T. G. Pottinger++, P. Sandøe** \& J. F. \\ Turnbull***
}

*Fish Biology Group, Institute of Biomedical \& Life Sciences, Graham Kerr Building, University of Glasgow, Glasgow, UK.

+Institute of Evolutionary Biology, University of Edinburgh, Kings Buildings, Edinburgh.

++ NERC Centre for Ecology \& Hydrology, Lancaster Environment Centre, Library Avenue, Bailrigg, Lancaster.

** Centre for Bioethics and Risk Assessment, University of Copenhagen, Rolighedsvej 25, Copenhagen, Denmark

***Institute of Aquaculture, University of Stirling, Stirling

\begin{abstract}
The welfare of fish is a topic of increasing debate touching on a number of complex scientific and ethical issues and constructive dialogue between groups with differing approaches to the topic requires mutual understanding from both perspectives. In a recent review aimed at stimulating debate on this topic, Arlinghaus et al. (2007) explore the question of fish welfare in the particular context of recreational angling, by means of a critique of a review of fish welfare in general written by ourselves (Huntingford et al. 2006). We entirely agree with the desirability of debate on this topic and recognise a number of valuable qualities in the commentary by Arlinghaus et al. However, we argue that the critique has some serious flaws. In the first place, by rejecting a feelings-based approaches to welfare, it fails to address the aspect of welfare that is at the heart of much legitimate public concern. Secondly, while advocating an objective, scientific approach to fish welfare, Arlinghaus and co-authors fail to present their own agenda (that recreational angling is morally acceptable) in a transparent way. Thirdly, they seriously misrepresent the position taken in Huntingford et al. (2006) on a number of important issues. In this reply, we address these points and then discuss briefly the areas of agreement and constructive disagreement between the two reviews.
\end{abstract}

Keywords: Angling, animal welfare, environmental ethics, feelings-based approach, recreational fisheries

\footnotetext{
${ }^{1}$ The reference of the printed version is:

Felicity Huntingford, Colin Adams, Victoria A. Braithwaite, Sunil Kadri, Tom G. Pottinger, Peter Sandøe \& James F. Turnbull (2007): The implications of a feelings-based approach to fish welfare: A reply to Arlinghaus et al. Fish and Fisheries 8: 277-280

The definitive version is available at http://onlinelibrary.wiley.com/doi/10.1111/j.1467-2679.2007.00254.x/abstract
} 


\section{Introduction}

In order to facilitate constructive dialogue between groups with differing approaches to the welfare of fish, or indeed of any animal, it is important that we aim for mutual understanding from both a scientific and an ethical perspective. Scientific information is essential in reaching moral decisions and, ideally, the scientific knowledge used to underpin such decisions should be presented without moral judgement. However, science cannot stand alone, so this ideal is seldom realised and scientists often bring to their work a personal perspective on moral issues. In such cases, scientific knowledge should be presented in a transparent, clearly stated moral context. In their recent review, Arlinghaus et al. (2007) explore the question of fish welfare with specific reference to recreational angling, by means of a critique of a general review of fish welfare written by ourselves (Huntingford et al. 2006). We argue that they fail to distinguish clearly between moral assumptions and scientific facts and that this clouds discussion in an otherwise interesting commentary.

Arlinghaus and his co-authors present a valuable, detailed and comprehensive review of the relevant literature on a very interesting topic that merits discussion, namely the implications of angling as a leisure pursuit, as opposed to fishing for food, and the role of humans as natural predators of fish. The critique is also valuable in highlighting some imprecision in our summary of the literature of the effects of angling on fish welfare. These have already been drawn to our attention and a corrected version of the relevant table has been published (Corrigendum. Journal of Fish Biology 2007, 70, 1311-1316). However, in addition to these valuable points, the critique has some serious flaws. In the first place, by dismissing feelings-based approaches to welfare, Arlinghaus and co-authors also dismiss exactly the aspect of welfare that is at the heart of much legitimate public concern about what happens to animals. Secondly, while advocating an objective, scientific approach to fish welfare, these authors fail to present in a transparent way their own moral agenda, which is that recreational angling in most of its present forms is morally acceptable. Thirdly, Arlinghaus and co-authors seriously misrepresent the position taken in Huntingford et al. (2006). We address these points in turn before briefly considering the areas of agreement and constructive disagreement between the two reviews.

\section{Keeping feelings out of welfare science}

The reason why in our review we emphasise welfare as defined by the absence of suffering (i.e. why we used a feelings-based definition) is that this definition comes closest to capturing the focus of public concern about the impact of human activity on animals. Such legitimate concern is one of the key forces driving the current debate on the welfare of animals, including fish. It is also clearly reflected in various forms of animal welfare legislation (national and international) that explicitly requires animals to be protected against 
suffering. We should not side-step the issues raised by such concern for the feelings of animals, no matter how difficult it is to determine objectively what animals may experience and however much this might impact on our personal interactions with them, whether these involve scientific research, aquaculture or angling. If biologists working in the field of animal welfare limit their consideration to the empirical study of functional aspects of welfare only, they are at risk of producing information irrelevant to the ethical concerns that provide a major justification for research into fish welfare. Therefore when Arlinghaus and co-authors reject a feelings-based approach to fish welfare, they are rejecting an important perspective on animal welfare defined by the society that pays for most welfare research.

\section{Unacknowledged biases}

Arlinghaus and co-authors criticise Huntingford and co-authors for what they perceive (incomprehensibly to us, see below) as an animal liberationist bias. However, statements throughout their review make it clear that they themselves come to this topic with the preconceived moral view that recreational angling is acceptable. Thus: "We proceed from the assumption that the use of fish is part of human evolution and therefore, in principle, a morally justified practice to satisfy consumptive and non-consumptive needs." (Arlinghaus et al. 2007. Page 63). Here Arlinghaus and co-authors make their moral position explicit. To give just one of many possible examples where their view is implicit, they make the following statement: "The scientific uncertainty regarding pain perception in fish ...is acknowledged by Huntingford et al. (2006) ...This theoretically at least - leaves the readers the option of drawing their own conclusions about the assumptions underlying the views expressed, but, nevertheless, provides misleading signals." (Arlinghaus et al. 2007. Page 59). The term "misleading signals" here implies that there is an already-known correct position and suggests that the authors have concluded in advance that there are correct and incorrect positions. If the conclusions are scientific, the evidence should be used to test hypotheses; provided the evidence is derived from robust science, it cannot be misleading. If the conclusions are moral, then Arlinghaus and co-authors must derive their definition of correct and incorrect from a pre-existing ethical perspective that should be explicitly stated. They do neither.

\section{Misrepresentations}

As stated above, Arlinghaus and co-authors make a number of claims about the views expressed in Huntingford et al. (2006) that simply do not reflect either our position or how it was presented. In what follows, we summarise and comment on some of the most striking examples. 
a) As an unavoidable consequence of taking a feelings-based approach, Huntingford et al. (2006) are guilty of anthropomorphism. Taking the view that fish may well have the physical, physiological and cognitive capacity to experience positive and negative mental states (as we do) is simply not equivalent to anthropomorphism. There is no necessary distinction between a feelings-based approach to fish welfare and a perspective that focuses on scientific facts. It is clearly possible to say, as we do, both that animal welfare is to be defined in terms of feelings and that animal welfare should be studied on the basis of scientific facts about behaviour. It may well be more difficult to devise ways of studying objectively the existence and nature of subjective experience in non-human animals than it is to find ways of measuring objectively their health or endocrine status (for example). However it can be done, for example by means of behavioural tools designed to study the cognitive capacities of animals, an approach that has been used widely and successfully in research on the welfare of terrestrial animals (e.g. Dawkins 2006, Duncan 2006).

b) By advocating a feelings-based approach, Huntingford et al. (2006) take an animal liberationist stance. In their Box 1 and the associated text, Arlinghaus and his co-authors equate our focus on feelings-based definitions to an "applied animal liberation philosophy" (Arlinghaus et al. 2007. Page 60). This seriously misrepresents our clearly-stated position. The argument would seem to run: Huntingford and co-authors advocate a feelings-based approach to fish welfare. Animal liberationists advocate a feelings-based approach to animal welfare. Therefore Huntingford and co-authors are animal liberationists. This is based on a logical fallacy of the most basic kind. It also confounds two quite separate issues, recognised as such by Arlinghaus and co-authors at several points in their review, but still conflated here. On the one hand, there is the scientific issue of how best to define and measure fish welfare. On the other, there is the moral issue of what is the appropriate action if welfare (however defined) is compromised. We state explicitly in our review that it is not the job of the scientist to make judgements as to what is acceptable or unacceptable and we are careful to avoid making any judgements in our review. For example: “...biologists may be able to tell us whether the welfare of fish is compromised by a certain human activity and even perhaps by how much, but normally they have neither the expertise needed for, nor the responsibility of deciding whether, the human activity is justified." (Huntingford et al. 2006. Page 335). There are many highly respected scientists studying animal welfare (e.g. Dawkins 2006; Duncan 2006) who accept and defend a feelings-based approach (while fully recognising the difficulties involved). One can challenge such views, but to do so by claiming that that these equate to an animal liberationist view is clearly absurd.

c) Huntingford et al. (2006) take an anti-angling position. The critique states in a number of places that we are arguing for a ban on recreational angling. For example: "By focussing on feelings and emotions... Huntingford et al (2006)...implicitly or explicitly argue against most human interactions with fish that are not primarily driven by the need to consume fish as food." (Arlinghaus et al. 2007, Page 61). This is simply not the case. In our review, which incidentally was written by a team including keen anglers as well 
as those who do not support angling, we were careful to stress that we make no judgements on what was right or wrong. Thus in our section on the costs and benefits of human interactions with fish we state: "This review does not aim to make judgements about what is acceptable and what is unacceptable ..." (Huntingford et al. 2006. Page 342). On the contrary, we explicitly discuss the benefits arising from humanfish interactions (including angling). It was not the remit of our review to discuss the many steps that stakeholders (scientists, anglers or fish farmers) can and have taken to ameliorate the effects of their activities on fish welfare, but recognition of the benefits of various human-fish interactions is reflected in our advocacy of a cost-benefit approach. Thus: "There is therefore every reason to seek a better empirical understanding of fish welfare and to give careful thought to how we should weigh the welfare of fish against the interest of humans when these are in conflict." (Huntingford et al. 2006, page 335).

d) Huntingford et al (2006) take the view of "natural (being) good" (Arlinghaus et al. 2007. Page 62). It is not quite clear where this interpretation comes from, since nowhere do we express this point of view, except when describing (but not endorsing) nature-based definitions of welfare. In fact, in our section entitled "Natural threats to wild fish" we state explicitly that: "what is natural is not necessarily good", pointing out that: "wild fish experience injury, poor environmental conditions and stressful events as a result of ...(various circumstances)." (Huntingford et al. 2006. Page 345). We certainly acknowledge a moral distinction between adverse conditions caused by natural events and those caused by human activity, especially when the fish concerned is unable to escape (Huntingford et al. 2006. Page 345). We also state that the fact that fish may experience adverse conditions in their natural habitats does not in itself justify humans imposing such conditions on fish (Huntingford et al. 2006. Page 332). However, this is not the same as saying that what is natural (and only what is natural) is good.

\section{Areas of agreement and of constructive debate}

We would argue that, once these more striking misrepresentations are put to one side, our review and that of Arlinghaus and co-authors are in fact in good agreement on many points. There are also areas where our views are genuinely different, providing appropriate topics for robust debate.

Concerning areas of agreement, both groups of authors would agree that the wellbeing of fishes is important, that it can be compromised by human activities (including recreational angling) and that it should be (and is) of concern to stakeholders. There is also agreement that various aspects of angling can have potentially negative impacts on fish, for example that hooking can, and sometimes does, cause physical damage, that playing and landing can, and sometimes does, cause physiological stress and physical exhaustion, that handling can, and sometimes does, cause damage, physiological stress and impaired function, that retention 
in keep nets can, and sometimes does, cause stress and that fish can be, and sometimes are, disoriented on release.

Concerning areas of genuine difference, Arlinghaus and co-authors make their comments about our position on what is natural and what is good in the context of an interesting discussion of humans as natural predators of fish. Additionally, the two reviews disagree in their interpretation of the complex literature on consciousness in fish and their capacity for pain and suffering, though both groups conclude that further research is needed on whether fish have the cognitive capacities for suffering. These are both areas for productive debate.

Ironically perhaps, the two reviews also agree on the desirability of making a clear distinction between scientific facts and ideological positions. Thus, Arlinghaus and co-authors state that "By contrast (..to defining good welfare as the preservation or enhancement of fish health..), the science underlying the feelings-based approach to fish welfare appears to be ideologically driven, striving to 'prove' what has to be the case, namely suffering in the interaction of fish with the 'non-natural' human. We contend that such dogmatic positions do not offer a constructive approach." (Arlinghaus et al. 2007. Page 67). We agree entirely with the last sentence. However, objective reading of Huntingford et al. (2006) will fail to find evidence of a dogmatic position. The declared objective of the review by Arlinghaus and co-authors was "To stimulate discussion about how to view and address issues in fish welfare" (Arlinghaus et al. 2007. Page 58). We fully endorse this objective and hope that, by making clear the misrepresentation of our views evident in their review, we can pave the way for future constructive exploration of the issues underpinning fish welfare.

\section{References}

Arlinghaus, R., Cooke, S.J., Schwab, A. and Cowx, I.G. 2007. Fish welfare: a challenge to the feelings-based approach, with implications for recreational fishing. Fish \& Fisheries, 8, 57-71.

Dawkins, M.S. 2006. Through animal eyes: What behaviour tells us. Applied Animal Behaviour Science 100, 4-10.

Duncan, I.J.J. 2006. The changing concept of animal sentience. Applied Animal Behaviour Science 100, 1119.

Huntingford, F.A, Adams, C.E, Braithwaite+,V.A, Kadri, S, Pottinger, T.G, Sandoe, P. \& Turnbull, J.F. 2006. Current issues in fish welfare. J. Fish Biology 68, 332-372. 